\title{
The Perceived Level of Collaborative Environment's Effect on Creative Group Problem Solving in a Virtual and Distributed Team Environment
}

\author{
Karoly Bozan \\ Idaho State University \\ bozakaro@isu.edu
}

\begin{abstract}
Continuous product development and market introduction of new products are central to sustaining company performance, and information systems (IS) development project managers face increasing pressure for quicker product delivery, despite cost constraints. To respond to these challenges, virtual and distributed $(V \& D)$ teams are formed, which present a unique environment to foster collaboration among the project team members. We investigated the sources and effects of team members' perceived level of collaboration on creative group problem solving in $V \& D$ IS project settings. Based on relational coordination theory, we performed semi-structured interviews and used a $Q$ methodology to confirm certain communication and relationship dimensions as precursors to collaborative environments. Using empirical tests, we found that relationships have a direct effect on creative group problem solving and that communication is mediated by perceived collaboration. We present practical implications and recommendations for V\&D IS project managers for enhancing creative problem solving for $V \& D$ IS projects.
\end{abstract}

\section{Introduction}

The continuous development of information systems (IS) and the provision of unique solutions to business challenges are key contributors to a company's competitive advantage and sustained performance [1-5]. Customers demand cutting-edge projects, and, to deliver them, companies need to respond to an ever-changing business environment [6]. In this regard, creativity is receiving increasing attention in the IS development context [7]. To achieve creative results that make an organization competitive, IS development needs the collaborative effort of individuals with unique skills, expertise, and insight [8]. Further, in response to time and cost constraints, IS development project managers often seek talent outside of organizational or geographic boundaries. This recent phenomenon involves virtual and distributed (V\&D) teams' collaborating using email, telephone, and collaboration software, such as Wrike, SmartSheet, Gantter, Zoho, Asana, Bitrix24, and so forth. Finally, project managers of V\&D teams need to understand the attributes of the environment in which team members work to promote the benefits that the combined knowledge and skills of all individuals offer [9-11].

The literature includes a number of definitions of V\&D teams [12-16] as including certain common characteristics, such as geographic dispersion or crossboundary collaboration [12, 17-24], driven by a common purpose $[12,13,19,20]$, and enabled by communication technologies $[17,18,22]$. Other characteristics of V\&D teams include temporary assignment [14, 19, 23-25], knowledge workers as team members $[19,26]$, and the use of contractors or other temporary consultant work relationships $[14,27]$

The literature also indicates that IS stimulates and enhances creativity [28]. Therefore, in this study, we investigate the antecedents of creative group problem solving during the IS development process, using a group rather than individual unit of analysis [38].

Gittel's relational coordination (RC) theory [29-32] found that the communication and relationship dimensions of work coordination positively affect team performance. Previous studies linked combining of diverse skills promoted creativity, which in turn, increased team performance. [33-37]. Thus, to better understand the collaborative environment and its effect on creative group problem solving, we grounded our research in RC theory. We followed this theory by identifying the communication and relationship drivers of a V\&D IS team. We performed semi-structured interviews and used a Q-methodology method [39, 40] to identify the communication and relationship dimensions of a collaborative work environment. Subsequently, we investigated the effect of a collaborative work environment on creative group problem solving. To this end, our research was guided by the following research questions:

- What are the communication and relationship dimensions in the V\&D IS project environment?

- To what extent does a collaborative work environment increase creative group problem solving? 
We propose a structural model to reveal the relationship among the previously identified constructs and empirically validate the proposed hypotheses. We also discuss the practical, methodological, and theoretical implications of this study.

\section{Research Design and Methods}

To evaluate the effect of perceived level of collaboration in a V\&D IS project context on creative problem solving as a group, we used the steps presented below:

1. We interviewed $84 \mathrm{~V} \& \mathrm{D}$ IS project members using a semi-structured interview protocol. The aim of the interview was to understand team members' perspectives on the attributes of a collaborative work environment that contributes to creative problem solving as a group.

2. We developed $42 \mathrm{Q}$-sort statements, derived from the interviews and grounded in RC theory. We asked respondents to sort the statements based on their level of agreement/disagreement on a -4 to +4 scale.

3. By-person factors were extracted to identify the respondent types and their perspectives on the attributes of an effective collaborative environment. The five factors retained represent a group of statements that characterize the respondents' perspectives. Of these five, three factors (transparent, consistent, and accountable/credible) were considered the communication dimensions of the perceived collaborative work environment, and two factors (trust, and shared values and expectations) were considered the relationship dimensions of the perceived collaborative work environment.

4. We proposed a structural model to represent the sources of the perceived level of a collaborative environment and its relation to creative problem solving as a group.

5. We investigated the mediating effect of the perceived level of a collaborative environment on creative group problem solving.

\subsection{Q-Methodology}

To explore the V\&D IS project team members' attitudes toward creative problem solving as a group, we used a Q-methodology [39, 40], a qualitativequantitative method used to explore, analyze, evaluate, and compare perspectives (e.g., viewpoints, opinions, beliefs, attitudes) in a holistic manner [41]. Specifically, Q-studies are designed to extract the different viewpoints of the participants while identifying the similarities and distinctions across all opinions.
We chose a Q-methodology over a Likert-type survey questionnaire because the Q-methodology allows participants to express their perceptions and meanings through sorting pre-developed general statements within previously identified domains. Q-sort, therefore, creates an operational medium sort [42] that circumvents the potential response biases that are found in self-report methods that utilize instruments developed through operational views of constructs and other theoretical formulations [43]. As Smith (p. 122) [44] stated, "Studies using surveys and questionnaires often use categories that the investigator imposes on the responses. Q, on the other hand, determines categories that are operant."

A Q-methodology involves a three-stage process [39, 47]:

1. Researchers develop a set of statements about the topic to be sorted. The Q-sort used for the sorting were developed by the research team using rigorous steps following the grounded analytical approach [45, 46]. We used constant comparison and selective, axial, and open coding in accordance with grounded theory principles [48, 49]. Using Dedoose a qualitative data analysis software, for our multiple round coding and analysis activities, we identified the categories and subcategories of creative problem solving as a group in a V\&D IS project environment as perceived by project team members across different functional areas within the project. These categories formed the basis of the development of the Q-sets, which contained the Qstatements that were to be organized by respondents to reveal their viewpoints.

2. The participants sort the statements into agree, disagree, and neutral decks and then further classify them within the agree-and-disagree spectrum. By sorting the statements from least to most agreement, they give meaning to the statements and reveal their viewpoints $[44,50]$.

3. Finally, these individual rankings are subjected to by-person factor analysis [51]. By correlating people's sorting order responses, by-person factor analysis provides insight into similarities and differences in regard to a topic. The resulting factors are clusters of subjectivity that represent functional rather than purely logical dissimilarities [39, 52]. Qmethodology fits our approach well, as these clusters or segments provide insight into the nature of respondents' subjectivity and the extent to which they are dissimilar or similar.

We received multiple factors (18-29) for each defining sort with composite reliability $>0.89$. Variance 
explained in each segments ranged between $9 \%$ and $17 \%$.

The qualitative translations of the factors resulted in transparent, consistent, and accountable / credible communication. We also determined two factors that represent the relationship dimension: trust and shared values and expectation.

\section{Research Model and Hypotheses}

We propose a theoretical model, shown in Figure 1, of the effect of communication and relationship factors on creative group problem solving in a V\&D IS project team environment. Although other factors may be involved in creative group problem solving, for the purposes of this study, we evaluate the factors related only to communication and relationships and their impact on the perceived level of a collaborative environment as antecedents to creative group problem solving.

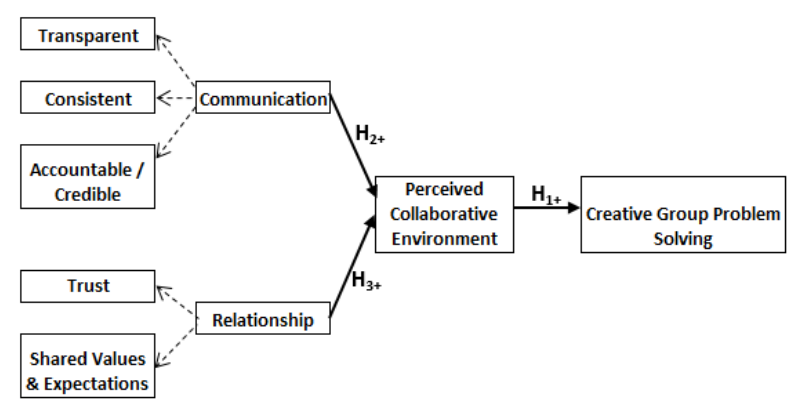

Figure 1. Proposed theoretical model

\subsection{Perceived collaboration in a V\&D IS project environment}

Collaboration is necessary in a work environment with high task interdependency. Johnson and Johnson [53] noted that working in a collaborative team environment fosters significant learning gains and creative problem solving. For the purposes of this study, we define a collaborative environment as a work setting in which individuals deliver their tasks in a way that satisfies the interests of other individuals dependent on the deliverable. In the context of V\&D IS development teams, members have specialized skills necessary for the success of the final product. Although certain tasks are completed by individual members, the work product is dependent on others' deliverables [54].

\subsection{Perceived collaborative environment and creative group problem solving}

Creativity refers to the creation of new and novel ideas in any domain $[55,56]$. Drazin, Glynn, and Kazanjian
[88] defined creativity in the IS domain as the degree to which a project team's processes are novel in the context of the project's objectives. Perry-Smith and Shalley [89] found that team creativity is a social process emerged from individual contributions. Tiwana and McLean [7] proposed in their expertise integration and creativity study in the IS domain that collaborative environment is a necessity for team creativity due to interrelation of ideas and unique skills. As noted by Amabile et al. [57], many factors affect creativity at the workplace; in this study, however, we focus on the relationship between the perceived collaborative environment and creative group problem solving. Because the work environment is found to be a stimulant to creativity [57-60,7], we hypothesize:

H1: A higher level of the perceived collaborative work environment will increase the level of creative group problem solving.

\subsection{Antecedents of collaborative work environment}

Creative group problem solving depends not only on a team's being composed of complementary knowledge and expertise alignment but also on the level of relational capital that individuals build during the project [7] and the communication among members to enhance work group innovation 61]. The facilitation of creative group problem solving can be particularly difficult in a V\&D work environment.

Communication as a precursor to teamwork outcomes has been studied by numerous scholars in a variety of industries and contexts [62-65] and has been linked to product innovation [66]. In a V\&D IS project environment, communication is especially important due team members' dispersion across geographic, temporal, cultural, and organizational boundaries.

As noted, to coordinate team members' individual efforts and inputs, V\&D IS project team managers make extensive use of communication technologies [17, 18]. As a result of our semi-structured interviews and Qmethodology evaluation method, we found that the common attributes of these technologies were their ability to support transparent, consistent, and accountable/credible communication. These indicators are aligned with Gittel's [29, 30] RC framework, which proposes frequency, timeliness, accuracy, and problemsolving ability as dimensions of communication. In this regard, we posit:

H2: A higher level of perceived communication will positively influence the perceived level of a collaborative work environment. 
The indictors of the relational dimension were previously identified through our Q-factor analysis. We found that the extent of trust and shared values and expectations define the relationship in a team environment. These indicators are aligned with Gittel's [29] RC framework, which proposes shared goals, shared knowledge, and mutual respect as relational dimensions. In this regard, we postulate:

H3: A higher level of a perceived relationship will positively influence the perceived level of a collaborative work environment.

\subsection{Measurement of the level of perceived collaborative work environment}

Following studies that employ RC $[29,32]$ as an indicator of satisfaction or performance outcome, we used a composite score to measure the extent to which V\&D IS project team members perceive their project's environment to be collaborative. We adopted the measures from Gittel's [29, 32] survey items and modified them to our researcher-developed communication (transparent, consistent, and accountable/credible) and relational (trust, and shared values and expectations) constructs.

\section{Research Methodology}

Projects were chosen based on a variety of factors. We targeted V\&D IS projects based on similar coordination complexities, and, because we considered task interdependence as a major factor, we utilized Thompson's classic typology [54]. The common stakeholder groups across the chosen projects were the project managers (PM), business analysts (BA), developers (DEV), end users (EU), and quality assurance team or testers (QA). The common objects on which they reciprocally depended were requirements, functional design, technical design, test cases, defect track log, and end user documentation. We initially met with eight project managers from three different industries: healthcare, professional services, and logistics, and explained the purpose of the research. They managed small- to medium-sized projects, including IS implementation and maintenance projects that involve all phases of the software development life cycle. The teams are partially or entirely distributed geographically and include contractor team members who are not full-time employees of the firm to which the project is delivered. Therefore, the V\&D IS project teams experienced relatively high turnover between projects, which posed additional challenges for project managers. The managers were chosen from the authors' professional network and agreed to support the project by providing management sponsorship and allocating time for their team members to meet with the research team. The teams were small- to medium-sized and included 12 to 28 people across the previously identified stakeholder groups.

\subsection{Measurement Development and Survey Administration}

Measurement items were adopted from the relevant literature and altered for the context and purposes of this study. For indirect, reflective measurement items, respondents were asked to use a 5-point Likert scale (1 $=$ strongly disagree, $5=$ strongly agree). We administered a pilot study to five project managers and asked for feedback. We reviewed the feedback and finalized the survey, which consisted of eight main measurement items and two items for control variables. The level of the perceived collaborative environment was measured by five questions, one for each item identified through our by-person factor analysis. Each of the identified items, however, had a subsection with five additional questions, which concerned the same measurement item but as related to other stakeholder groups. The three measurement items for creative group problem solving were adopted from Tiwana [7]. Overall, there were 30 items, which we distributed among the six V\&D IS projects in the form of a link to an online survey, for which the initial page provided consent and explained definitions. Participation was voluntary, and we received 91 responses during our data collection in January 2016.

\section{Data Analysis and Results}

Partial least squares (PLS) was used to validate and test our measurement and structural models, for which we used SmartPLS Statistical Software for Structural Equation Modeling (version 3.2.1 Windows 64 bit). The PLS statistical method, a component-based latent structural equation modeling technique, provides more flexibility in terms of sample size and residual distribution [67-69].

\subsection{Measurement Validation}

Following common practice in PLS-PM analysis, we first investigate the reliability and validity of the measures used to represent the latent variables [70]. As required by PLS-PM, all indicator variables relate positively to their respective latent variables [71].

We achieved internal consistency that exceeded 0.90, which was considered adequate for all principal constructs. Construct validity was tested through convergent (items that should be related are, indeed, 
related) and discriminant (items that should not be related are, indeed, not related) validity checks. We found that correlations among all constructs were below 0.90 but, to an extent, were related, and almost all were statistically significant at the $p<0.05$ and $p<0.01$ levels. The square root of average variance extracted (AVE) was greater than that of any other crosscorrelations, and AVEs were greater than 0.5, which indicates that the principal constructs capture higher construct-related than error-related variance. Principal component factor analysis showed that all items loaded on their corresponding constructs and with higher factor loadings than cross-loadings, while confirmatory factor analysis confirmed that items loaded to their principal constructs with clear loading patterns.

We tested for common method bias that, due to something external to the measures, may occur in selfreport questionnaires. Specifically, bias can occur when one factor accounts for most of the variance, based on item construction, item order, audience, scale used, and so forth [72]. As per Podsakoff et al. [72], we employed Harman's single-factor test, using exploratory factor analysis, as seen in the literature [73-77]. This resulted in nearly equal variance loadings across the factors and, thus, no indication of common method bias. The previously determined correlation among constructs did not show an extreme correlation $(>0.90)$, as the highest construct correlation was 0.68 . We also tested for partial correlations, as recommended by Podsakoff et al. [72], adding the highest loaded factor into the PLS model as another control. None of the dependent variables increased significantly, and, as such, no common method bias was indicated.

\subsection{Control Variables}

We chose two control variables from the literature: technological uncertainty and project stage [7]. Technological uncertainty refers to the phenomenon in which skills and resources change to better adapt to the challenges of the project. A measurement scale, adopted from Poppo and Zenger [78], showed that team members who undertake projects characterized by higher technological uncertainty are more likely to use creative methods to address challenges. Project stage at the time of survey was asked in $20 \%$ increments $(0-20 \%$ $=$ initial phase, $20 \%-40 \%=$ requirements gathering and design phase, $40 \%-60 \%=$ development phase, $60 \%-$ $80 \%=$ testing/deployment phase, $80-100 \%=$ maintenance phase). As recommended by Tiwana and McLean [7], with this control variable we control for the possibility that team members use different levels of creativity in different stages of the project.

We excluded the potential confounding effect of the history of working together [79]. Specifically, we excluded this variable as it may be correlated to both the independent and dependent variables. Therefore, we studied team members involved in projects that were formed for the purpose of the deliverable on which they were working on at the time of the survey.

Limited missing values were returned for these control variables, handled through the mean imputation method [80]. Prior to our research model analysis, we performed a complete control variable analysis. Control variables had a significant relationship with at least the endogenous variables and, to ensure that their effect was accounted for, were included in the final structural model. Their effect is statistically significant, but they had limited effect on the structural model's endogenous variables, measured through a change in the coefficient of determinants with and without the control variables $\left(\Delta R^{2}<0.1\right)$.

\subsection{Structural Model Test}

We tested the structural model against the hypotheses through path coefficients, statistical significance, and $R$-squared value. Path coefficients concern the strength of the relationship between the independent and dependent variables, and $R$-squared values indicate the predictive power of a model [81]. We used a nonparametric bootstrapping technique to calculate the $t$-statistics values in SmartPLS to determine the statistical significance of the path coefficients $[82,83]$. We used the full sample to test the six hypotheses that we developed. The standardized PLS path coefficients, $R_{2}$, total and mediated effects, and control variables used to test the structural model are shown in Figure 2.

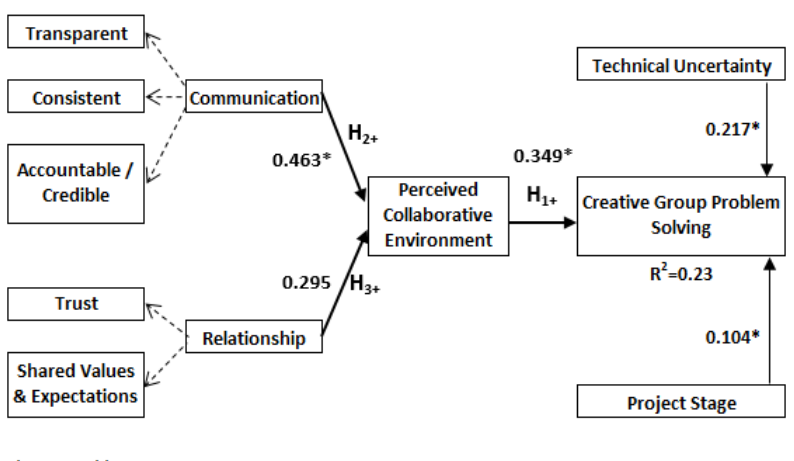

Figure 2. Path coefficients in the structural model

The standardized regression coefficients are generated first, followed by bootstrapping. Resampling with replacement at least 1,000 times is necessary for valid $t$-values, as suggested by Chin et al. [84]. $R$ squared $\left(R_{2}\right)$ values are reported for endogenous construct, as suggested by Hulland [85]. 
As hypothesized, the perceived collaborative environment has a significant positive direct effect on creative group problem solving $(b=0.349, p<0.05)$, explains 23 percent of its variance, and supports $\mathrm{H} 1$. The communication construct has a significant and relatively strong positive effect on the perceived collaborative environment $(b=0.463, p<0.05)$, explains 29 percent of its variance, and supports H2. The relationship dimension did not indicate a significant positive effect on the perceived collaborative environment $(b=0.295$, $p>0.05$ ) and did not support $\mathrm{H} 3$.

\subsection{Mediation Analysis}

Mediation is seen when an intervention influences an outcome and has a temporal and causal relationship. Mediation analysis can be used to determine a more successful and cost-effective approach when it is developed using a prior theory and within the appropriate context.

When a predictor variable's significant effect on the outcome variable weakens through the introduction of a mediator, an indirect or mediated effect is supported [86]. Full or complete mediation is seen when the significant effect between the predictor and outcome variables become zero when the mediator variable is added. If the effect or relationship is reduced in size, then one sees partial mediation [87].

To test the mediating effect of a perceived collaborative environment, we used Baron and Kenny's [86] test for mediation with two additional models. The first model excluded the perceived collaborative environment mediator, enabling us to directly link the communication and relationship dimensions to creative group problem solving. The second test model involved the mediator of a perceived collaborative environment but also included a direct link from the communication and relationship dimensions. We found that communication had a significant effect on creative group problem solving when not mediated by a perceived collaborative environment but an insignificant effect on creative group problem solving when not mediated by a perceived collaborative environment.

\section{Discussion}

The overarching goal of this paper was to understand the sources of collaborative work environments and evaluate their mediating effect on creative group problem solving in the V\&D IS development context. Our research was grounded in RC theory and explored its possibilities from a V\&D IS development perspective. Our approach, theoretical framework, and findings extend the literature and provide significant implications to academia and practice.

Our Q-methodology approach is a unique way of evaluating the V\&D IS project team members' viewpoints on the collaborative and creative environment of their project. Our approach covered all major stakeholders in the project, and, therefore, we obtained a complete evaluation of the team members' perspectives. As a result of our Q-methodological analysis, we found trust and shared values and expectations the sources of relationship. This reflects what the literature [7] shows. Tiwana \& McLean [7] measured relational capital through trust, mutual respect, and high reciprocity. Gittel's [29] relational dimensions include shared goals, shared knowledge, and mutual respect. We adopted a mic of these measurement items from the literature in our survey.

Following the literature, we theoretically developed the idea that the perceived collaborative environment mediates the relationship between the communication dimension and creative group problem solving, which was our outcome variable. We also found that the relationship dimension, a hypothesized dimension of perceived collaborative environment, was found to have a direct effect on creative group problem solving.

The direct effect of the relationship dimension on creative group problem solving has important implications for managers in the V\&D IS project setting. First, we found that trust and shared values and expectations, the direct measures of a relationship, among project stakeholders have an immediate and direct effect on creative group problem solving. In contradiction, Tiwana \& McLean [7] found relational capital's indirect effect on creativity. Because the literature did not establish this direct connection, our findings extend the literature and have implications for practice. V\&D IS project managers should consider that nurturing and encouraging the relationship of geographically dispersed team members have a positive direct effect on creative group problem solving. Therefore, the dimensions (1) trust and (2) shared values and expectations need to be created and encouraged. Project managers actively need to be involved in the group and individual communications to encourage respectful interactions and clarifications on the mutually agreed upon expectations. The shared goals and expectations coupled with trust may promote unique and novel solutions to better accomplished the goals.

The other findings of the test of our structural model revealed that communication is mediated by the perceived level of the collaborative work environment. The three indicators of communication, namely transparent, consistent, and credible/accountable, have a direct effect on the perceived level of collaboration. In turn, the higher the perceived level collaboration, the higher the creative group problem solving will be. 
Therefore, our findings suggest that V\&D IS project managers should provide the technological support that enables and, on occasion, mandates V\&D IS project team members to communicate their progress status, the issues they face, and the tasks they work on and wait on and to share knowledge. Such communication will keep other members updated, allow challenges to surface, and enable the sharing of expertise, all of which increase the perceived level of collaboration among V\&D IS project team members.

\section{Limitations and Future Research}

Although we extend the literature by exploring the driving forces of creative group problem solving in the V\&D IS development project setting, there are several limitations of our study. First, it must be noted that there are numerous well-studied other antecedents of creativity at both the organizational and individual levels. We focused on only a subset of factorscommunication and relationship - that influence, both directly and indirectly, creative group problem solving. This is clearly indicated by the relatively low $\mathrm{R}^{2}$ values.

We depended on V\&D IS project team members' subjective input with regard to the outcome variable, creative group problem solving. We used established measures [7, 78] to assess creativity based on respondents' input; however, because they rated creativity on their own work, there is the potential for bias. Thus, it may better to depend on the project managers' input exclusively for this construct. Further, the variance modeling in this study concerned the creativity of the team's process. A true process observation for creativity would require longitudinal data.

Although the unexpected direct effect of the relationship dimension on the dependent variable is an important finding of this study, future research should using different project sizes and other attributes to study creative group problem solving

\section{Conclusion}

An understanding of the sources of a collaborative work environment, in view of $\mathrm{RC}$, and their direct and indirect effects on creative group problem solving could provide benefits for organizational creativity. Notably, the collective creative problem solving of team members depends on the proper environment created by transparent, consistent, and accountable / credible communication with the use of technology. On the other hand, project manager fostered relationship based on trust and shared values and expectations directly influence the group level creative problem solving.

\section{References}

[1] Blundell, R., Griffith, R., Reenen, J., "Market share, market value and innovation in a panel of British manufacturing firms", Review of Economic Studies, 66(3), pp. $529-554$.

[2] Brockhoff, K., Produktpolitik, 4th edition. Stuttgart: Lucius \& Lucius. 1999.

[3] Capon, N., Farley, J.U., Hoenig, S., "Determinants of financial performance: a metaanalysis", Management Science, 36(10), 1990, pp. 1143-1159.

[4] Chaney, P.K., Devinney, T.M., "New product innovations and stock price performance", Journal of Business, Finance and Accounting, 19(5), 1992, pp. 677-695.

[5] Urban, G.L., Hauser, J.R., Design and Marketing of New Products, 2nd edition. Upper Saddle River, NJ: Prentice Hall. 1993.

[6] Bergiel, J.B., E.B. Bergiel, P.W. Balsmeier, "Nature of virtual teams: a summary of their advantages and disadvantages", Management Research News, 31(2), 2008, pp. 99-110.

[7] Tiwana, A., Mclean, E. R., "Expertise Integration and Creativity in Information Systems Development," Journal of Management Information Systems, 22(1), 2005, pp. 13-43.

[8] Munkvold, B.E., Zigurs, I., "Process and technology challenges in swift-starting virtual teams", Information and Management, 44(3), 2007, pp. 287-299.

[9] Badrinarayanan, V., Arnett, D.B., "Effective virtual new product development teams: an integrated framework", Journal of Business and Industrial Marketing, 23:, 2008, pp. 242-248.

[10] Prasad, K, Akhilesh, K.B., "Global virtual teams: what impacts their design and performance?", Team Performance Management, 8:, 2002, pp. 102 - 112.

[11] Badrinarayanan, V., Arnett, D.B., "Effective virtual new product development teams: an integrated framework", Journal of Business and Industrial Marketing, 23:, 2008, pp. 242-248.

[12] Gassmann, O., Von Zedtwitz, M., "Trends and determinants of managing virtual R\&D teams", $R \& D$ Management, 33(3), 2003, pp. 243-262.

[13] Hertel, G.T., Geister, S., Konradt, U., "Managing virtual teams: A review of current empirical research", Human Resource Management Review, 15(1), 2005, pp. 69-95.

[14] Leenders, R., Engelen J., Kratzer, J., "Virtuality, communication, and new product team creativity: a social network perspective", Journal of Engineering and Technology Management, 20(1), 2003, pp. 69-93. 
[15] Lurey, J.S., Raisinghani, M.S, “An empirical study of best practices in virtual teams", Information and Management, 38(8), 2001, pp. 523-544.

[16] Powell, A ., G. Piccoli, Ives, B., "Virtual teams: a review of current literature and directions for future research", The Database for Advances in Information Systems, 35(1), 2004, pp. 6-36.

[17] Peters, L.M, Manz, C.C., "Identifying antecedents of virtual team collaboration", Team Performance Management, 13(3/4), 2007, pp. 117-129.

[18] Lee-Kelley, L., Sankey, T. "Global virtual teams for value creation and project success: A case study", International Journal of Project Management, 26(1), 2008, pp. 51-62.

[19] Bal, J. and Teo, P.K., "Implementing virtual team working. Part 1: a literature review of best practice", Logistics Information Management, 13(6), 2001, pp. 346 - 352.

[20] Rezgui, Y., "Exploring virtual team-working effectiveness in the construction sector", Interacting with Computers, 19(1), 2007, pp. 96-112.

[21] Precup, L., O'sullivan, D., Cormican, K., Dooley, L., "Virtual team environment for collaborative research projects", International Journal of Innovation and Learning, 3(1), 2006, pp. $77-94$.

[22] Nemiro, J.E., "The Creative Process in Virtual Teams", Creativity Research Journal, 14(1), 2002, pp. 69 - 83.

[23] Paul, S., Seetharaman, P., Samarahand, I., Peter, J., Mykytyn, I., "Understanding Conflict in Virtual Teams: An Experimental Investigation using Content Analysis", 38th Hawaii International Conference on System Sciences, 2005, Hawaii.

[24] Wong, S.S., Burton, R.M., "Virtual Teams: What are their Characteristics, and Impact on Team Performance?", Computational and Mathematical Organization Theory, 6(4), 2000, pp. 339-360.

[25] Cascio, W.F., Shurygailo, S., "E-Leadership and Virtual Teams", Organizational Dynamics, 31(4), 2003, pp. 362- 376.

[26] Kirkman, B.L., Rosen, B., Tesluk, P.E., Gibson, C.B., "The Impact of Team Empowerment on Virtual Team Performance: The Moderating Role of Face-to-Face Interaction", Academy of Management Journal, 47(2), 2004, pp. 175-192.

[27] Dafoulas, G., Macaulay, L., "Investigating Cultural Differences in Virtual Software Teams", The Electronic Journal of Information Systems in Developing Countries (EJISDC), 7(4), 2002, pp. 1-14.

[28] Marakas, G., Elam, J., "Creativity enhancement in problem solving: Through software or process?", Management Science, 43(8), 1997, pp. 1136-1146.
[29] Gittell, J.H. "Organizing work to support relational coordination", International Journal of Human Resource Management, 11(3), 2000, pp. 517-539.

[30] Gittell, J.H., "Relationships between service providers and their impact on customers." Journal of Service Research, 4(4), 2002, pp. 299-311.

[31] Gittell, J.H., Weiss L., "Coordination networks within and across organizations: A multi-level framework." Journal of Management Studies, 41(1), 2004, pp. 127-153.

[32]Gittell, J. H., Relational coordination: Guidelines for Theory, Measurement and Analysis, Waltham, MA: Brandeis University. 2011.

[33] Hoegl, M., Parboteeah, K.P., "Creativity in innovative projects: How teamwork matters", Journal of Engineering and Technological Management, 24(1), 2007, pp. 148-166.

[34] Cohen, S.G., Designing effective self-managing work teams: theories of self-managing work teams. In: Beyerlein, M., Johnson, D. (Eds.), Advances in Interdisciplinary Studies of Work Teams, vol. 1. JAI Press, Greenwich, pp. 67-102. 1994.

[35] Kichuk, S.L., Wiesner, W.H., "The big five personality factors and team performance: implications for selecting successful product design teams", Journal of Engineering and Technology Management, 14(3), 1997, pp. 195-221.

[36] Hoegl, M., Weinkauf, K., Gemuenden, H.G., "Inter-team coordination, project commitment, and teamwork in multiteam R\&D projects: a longitudinal study", Organization Science, 15 (1), 2004, pp. 38-55.

[37] Taggar, S., "Individual creativity and group ability to utilize individual creative resources: a multilevel model", Academy of Management Journal, 45(2), 2002, pp. 315-330.

[38] Madjar, N., Oldham, G.R., Pratt, M.G., “There's no place like home? The contributions of work and non-work creativity support to employees' creative performance", Academy of Management Journal, 45(1), 2002, pp. 757-767.

[39] Brown, S.R., "A Primer on Q Methodology," Operant Subjectivity (16,3-4), 1993, pp. 91-38.

[40] Stephenson, W., The Study of Behavior. Chicago: University of Chicago Press. 1953.

[41] Akhtar-Danesh, N., Baumann A., Cordingley L., "Qmethodology in Nursing Research: Promising Method for the Study of Subjectivity," Western Journal of Nursing Research 30(6), 2008, pp. 759-773.

[42] McKeown B.F., Thomas B.D., Q-methodology, Newbury Park, CA: Sage Publications. 1998.

[43] Dennis, K.E., Goldberg, A.P., "Weight Control Selfefficacy Types and Transitions Affect Weight-loss Outcomes 
in Obese Women," Addictive Behaviors 21(1), 1996, pp. $103-$ 116.

[44] Smith N.W., Current systems in psychology: history, theory, research, and applications, Wadsworth, 2001.

[45] Boyatzis, R.E., Transforming Qualitative Information: Thematic Analysis and Code Development. Thousand Oaks, CA: Sage Publications, Inc. 1998.

[46] Braun, V., Clarke, V., "Using Thematic Analysis in Psychology," Qualitative Research in Psychology, 3(2), 2006, pp. 77-101.

[47] Valenta, A.L., Wigger, U., "Q-methodology: Definition and Application in Health Care Informatics," Journal of the American Medical Informatics Association, 4(6), 1997, pp. 501-510.

[48] Glaser, B.G., Strauss, A.L., Discovery of Grounded Theory: Strategies for Qualitative Research. Chicago, IL: Aldine Publishing Company. 1967.

[49] Strauss, A.L., Corbin, J., Basics of Qualitative Research: Grounded Theory Procedures and Techniques. Newbury Park, CA: Sage. 1990.

[50] Brouwer, M. Q., "Is Accounting for Tastes", Journal of Advertising Research, 39(2), 1999, pp. 35-39.

[51] Stephenson, W., "Introduction to inverted factor analysis, with some applications to studies in orexis," Journal of Educational Psychology, 27(5), 1936, pp. 353-367.

[52] Brown, S.R., "Structural and Functional Information," Policy Sciences 35(3), 2002, pp.285-304.

[53] Johnson, D.W., Johnson, R.T., Using cooperative learning in math. In N., Davidson (ed.), Cooperative Learning In Mathematics (pp.103-125). Menlo Park, California, USA: Addison-Wesley Publishing. 1990.

[54] Thompson, James D., Organizations in Action: Social Science Bases of Administrative Theory. New York: McGrawHill. 1967.

[55] Stein, M. I., Stimulating Creativity: Individual Procedures, Vol. I. New York: Academic Press, 1974.

[56] Woodman, R.; Sawyer, J.; Griffin, R., "Toward a theory of organizational creativity", Academy of Management Review, 18(2). 1993, pp. 293-321.

[57] Amabile, T. M., Conti, R., Coon, H., Lazenby, J., \& Herron, M., "Assessing the work environment for creativity", Academy of Management Journal, 39(5), 1996, pp. 11541184.

[58] Amabile, T. M., A model of creativity and innovation in organizations, In B. M. Staw \& L. L. Cummings (Eds.), Research in organizational behavior, Vol. 10. Greenwich, CT: JAI Press. 1998.
[59] Amabile, T. M., \& Conti, R., "Changes in the work environment for creativity during a downsizing", Academy of Management Journal, 42(6), 1999, pp. 630-640.

[60] Amabile, T. M., "Leader behaviors and the work environment for creativity: Perceived leader support", The Leadership Quarterly, 15(1), 2004, pp. 5-32.

[61] J. L. Farr, Sin, H. P., Tesluk, P. E., Shavinina, L. V., "Knowledge Management Processes and Work Group Innovation," in the International Handbook on Innovation, Pergamon, 2003, pp. 574- 586.

[62] Prencipe, A. \& Tell, F., "Inter-project learning: processes and outcomes of knowledge codification in project-based firms," Research Policy, 30(9), 2001, pp. 1373-1394.

[63] Szulanski, G., "Exploring internal stickiness: Impediments to the transfer of best practice within the firm", Strategic Management Journal, 17(2), 1996, pp. 27-43.

[64] Balbontin, A., Yazdani, B., Cooper, R. Souder, W.E., "New product development success factors in American and British firms", International Journal of Technology Management, 17(3), 1999, pp. 259-279

[65] Yap, C.M. Souder, W.E., "Factors influencing new product success and failure in small entrepreneurial hightechnology electronic firms", Journal of Product Innovation Management, 11(5), 1994, pp. 418-432.

[66] Maidique, M.O., Zirger, B.J., "A study of success and failure in product innovation: the case of the U.S. electronics industry", IEEE Transactions on Engineering Management, EM-31(4), 1984, pp. 192-203.

[67] Anderson, J.C., Gerbing, D.W., "Structural Equation Modeling in Practice: A Review and Recommended Two-Step Approach", Psychological Bulletin, 103(3), 1988, pp. 411423.

[68] Chin, W.W., Marcolin, B.L., Newsted, P.R., "A partial least squares latent variable modeling approach for measuring interaction effects: Results from a Monte Carlo simulation study and an electronic mail adoption study", Information Systems Research, 14(2), 2003, pp. 189-217.

[69] Chin, W.W., "Issues and opinion on structural equation modeling", MIS Quarterly, 22(1), 1998, pp. 7-16.

[70] Chin, W. W.. How to write up and report PLS analyses. In Esposito, V., et al. (eds.), Handbook of Partial Least Squares (pp. 655 -688). New York: Springer-Verlag. 2010.

[71] Sanchez, G., PLS Path Modeling with R. Trowchez Editions. Berkeley, 2013.

[72] Podsakoff, P.M., MacKenzie, S.B., Lee, J-Y., and Podsakoff, N. P. "Common Method Biases in Behavioral Research: A Critical Review of the Literature and 
Recommended Remedies," Journal of Applied Psychology, 88(5), 2003, pp. 879-903.

[73] Andersson, L. M., \& Bateman, T. S., "Cynicism in the workplace: Some causes and effects", Journal of Organizational Behavior, 18(5), 1997, pp. 449-469.

[74] Aulakh, P.S., \& Gencturk, E. F., "International principalagent relationships - control, governance and performance", Industrial Marketing Management, 29(6), 2000, pp. 521-538.

[75] Greene, C. N., \& Organ, D. W., “An evaluation of causal models linking the received role with job satisfaction", Administrative Science Quarterly, 18(1), 1973, pp. 95-103.

[76] Organ, D. W., \& Greene, C. N., "The effects of formalization on professional involvement: A compensatory process approach", Administrative Science Quarterly, 26(2), 1981, pp. 237-252.

[77] Schriesheim, C. A., "The similarity of individual-directed and group directed leader behavior descriptions", Academy of Management Journal, 22(2), 1979, pp. 345-355.

[78] Poppo, L., and Zenger, T., "Testing alternative theories of the firm: Transaction cost, knowledge-based, and measurement explanations for make-or-buy decisions in information services", Strategic Management Journal, 19(9), 1998, pp. 853-877.

[79] Tuttle, B., “A study of staff turnover, acquisition, and assimilation and their impact on software development cost and schedule", Journal of Management Information Systems, 6(1), 1989, pp. 21-40.

[80] Hair, J.F., Black, W.C., Babin, B.J., Anderson, R.E., Multivariate Data Analysis, Upper Saddle River, NJ: Prentice Hall; 2010.
[81] Barclay, D., Higgins, C., Thomson, R., "The partial least squares approach to causal modeling, personal computer adoption and use as an illustration", Technology Studies, 2(2), 1995, pp. 285-309.

[82] Efron, B., and Tibshirani, R. J., An Introduction to the Bootstrap, Chapman Hall: New York. 1993.

[83] Davison, A. C., and Hinkley, D. V., Bootstrap Methods and Their Application, Cambridge University Press: Cambridge. 1997.

[84] Chin, W.W., Marcolin, B.L., Newsted, P.R., "A partial least squares latent variable modeling approach for measuring interaction effects: Results from a Monte Carlo simulation study and an electronic mail adoption study", Information Systems Research, 14(2), 2003, pp. 189-217.

[85] Hulland, J., "Use of Partial Least Squares (PLS) in strategic management research: A review of four recent studies", Strategic Management Journal, 20(2), 1999, pp. 195-204.

[86] Baron, R. M., \& Kenny, D. A., "The moderator-mediator variable distinction in social psychological research: conceptual, strategic, and statistical considerations", Journal of Personality and Social Psychology, 51(6), 1986, pp. 11731182.

[87] Kenny, D. A., \& Judd, C. M., „Power anomalies in testing mediation”, Psychological Science, 25(2), 2014, pp. 334-339.

[88] Drazin, R.; Glynn, M.A.; and Kazanjian, R. "Multilevel theorizing about creativity in organizations: A sensemaking perspective." Academy of Management Review, 24(2), 1999, pp. 286-307.

[89] Perry-Smith, J., and Shalley, C. "The social side of creativity: A static and dynamic social network perspective." Academy of Management Review, 28(1), 2003, pp. 89-106. 